\title{
AUTONOMIA DOS MUNICIPIOS
}

"Os Estados organisar-se-ão por fórma que fique assegurada a autonomia dos municipios, em tudo quanto respeita ao seu peculiar interesse".

São os termos que prevaleceram entre os constituintes de 1891, terceiro da Republica.

O projecto do governo provisorio, da lavra de RUY BARBOSA, rezava:

Art. 67 - Os Estados organisar-se-ão por leis suas, sob o regimen municipal, com estas bases:

$\left.1 .^{\circ}\right)$ - A autonomia dos municipios em tudo quanto respeita ao seu peculiar interesse;

$\left.2 .^{\circ}\right)$ - Electividadie da administração local.

Art. 68 - Nas eleições municipaes serão eleitores e elegiveis os estrangeiros residentes, segundo as condições que a lei de cada Estado prescrever"

Emenda, proposta por LAURo SODRÉ, fundiu o artigo 67 e seus dois paragraphos no artigo 68 acima transcripto, e outra emenda, agora de Borges de Medeiros, supprimiu o artigo 68 do projecto.

Bem ou mal, estas emendas foram approvadas, e, hoje, entre nós, na organisação municipal, a lei suprema é a do artigo 68 da Constituição Federal, em que se prescreve a "autonomia dos municipios em tudo quanto respeita ao seu peculiar interesse" 


\section{ENTIDADES INCONSTITUCIONAES}

E' difficil texto de lei, em que o pensamento legislativo transpareça em linguagem mais limpida e mais crystalina. Não se inquire se pensaram bem ou mal os constituintes republicanos. E' possivel que mais avisados tivessem andado, se da norma geral da autonomia se excluissem certos municipios, como os das capitaes dos Estados. Mas não se trata, aqui, de direito a ser. $O$ de que se cuida, é do direito que é. A lei suprema do paiz ordena, acima de todas as vontades e de todas as leis, a "autonomia dos municipios em tudo quanto respeite ao seu peculiar interesse", sem a menor distincção entre elles. Nem sequer permitte ella a criação de circumscripções administrativas, que não sejam municipios como as prefeituras sanitarias de Minas, ou as de Guarujá, do Prata e dos Campos do Jordão. Estas entidades são corpos estranhos no organismo constitucional da Republica. A constituição de 24 de fevereiro determina, peremptoriamente, a organisação dos estados, sob o regimen municipal, isto é, sob um regimen em que as administrações locaes sejam autonomas "em tudo quanto respeite ao seu peculiar interesse" E tanto empenho poz nisto a constituição, que, ao tratar da intervenção federal nos estados, incluiu, entre os principios cujo desrespeito dá logar á intervenção, a autonomia dos municipios (art. 6: II).

\section{O CONCEITO DA AUTONOMIA}

Precisar o conceito da autonomia não é enigma que só decifrem os iniciados em sciencias occultas. Não é realidade que se desenhe muito para além das nuvens, como essas tramas de metaphysica, em que só a dialectica das abstracções conclue e decide. Mas realidade trivial, ao alcance de quem o queira.

A soberania, sabem todos, é poder supremo de autodeterminação. Um poder, "acima do qual não ha outro". 
E' o maior de todos. 'E' o supremo. Tem-lhe sido o titular ora um só homem, como nas monarchias absolutas á Luiz XIV, ora grupos de homens, como nas olygarchias á brasileira, ora os cidadãos 'eleitores, a nação, como hoje, nos Estados Unidos, na França e na Inglaterra, e como declara para o Brasil a sua constituição em vigor. Legitimamente só a nação é soberana. Só ella pode talhar para si a organisação politica que mais the praza. O unico limite (se a isto se pode chamar limite), opposto á soberania, é o direito. A soberania, não sè comprehende que seja o poder do crime. Mas quem determina o que é direito, isto é, quaes as balisas da soberània, é o proprio soberano. E', pois, um "poder supremo de auto-determinação"

A autonomia já não tem tamanha amplitude. " $E$ ' a direcção propria daquillo que lhe é proprio". '(João Mendes) Emquanto a soberania se esbarra com horizontes que ella só a si mesma traça, a autonomia se exerce entre muralhas intransponiveis, e estas muralhas não se geram na sua vontade. E' um poder maior que o seu, quem lhas impõe. Não é, por isto, um poder supremo como a soberania, mas um poder subordinado. Não se origina de si mesma, mas decorre de um poder mais alto. Em regra, da soberania. E' o poder de auto-determinação, dentro em barreiras que não determina.

Retire-se da autonomia a idéa de auto-determinação, ou governo proprio em competencia propria, mas que lhe fixam, e nada mais lhe sobrará. São os seus dois elementos essenciaes irreductiveis: as raias inviolaveis em que lhe circumscrevem a acção, e o poder de agir livremente dentro destas raias.

\section{O PRIMEIRO ELEMENTO: INTERESSES PECULIARES}

Os limites ao poder auto-determinante são o primeiro elemento da autonomia, que, por isto e só disto, se afasta. da soberania. 
A constituição federal asscgura aos municipios a direç̧ão propria da sua vida " $\mathrm{em}$ tudo quanto respeite ao seu peculiar interesse"

Nessa phrase final é que traçou as raias intransponiveis á extensão da autonomia municipal. Dentro de seu peculiar interesse, os municipios são senhores de si. Fóra destes interesses, neninuma voz activa podem ter.

E que é o que sc pode entender por peculiar interesse?

$\mathrm{O}$ interesse cu é peculiar, ou é geral, subdividindo-se este em estadual c nacional. A manutenção de uma esquadra de guerra é interesse não só do Rio de Janeiro, nem só do Amazonas, uu do Rio Grande do Sul. Mas de toda a nação. A marinha é, como as forças de terra, instituição nacional, destinada, nos termos do artigo 14 da constituição, "á defesa da patria no exterior, é a manutenção das leis no interior". A instituição de uma força policial, ou a abertura de uma estrada de rodagem não são interesses senão das regiões que as mantêm. São interesses regionaes, provinciaes ou estaduaes. $\mathrm{O}$ calçamento das ruas de uma cidade, ou a pastorização do leite que lhe é distribuido, são interesses peculiares dos seus habitantes, são interesses locaes ou municipaes.

Necessidades ha, em summa, cujo provimento aproveita directamente a todos, como a defesa militar do paiz. Outras ha, cuja satisfacção aproveita, immediatamente, a certos individuos, e, reflexamente, a todos, como o saneamento de um porto.

$\mathrm{Ha}$, entre parenthesis, nestas classificações, muito de puramente estimativo, e alguma coisa de arbitrario. A instrucção, por exemplo, interessa de tal modo á nação, que, embora os individuos que a recebam, sejam os primeiros beneficiados, não se póde com rigor havel-a por interesse apenas estadual ou municipal.

Pode, ainda, succeder que, no mesmo local, necessidades haja de todas as categorias. Em qualquer recanto sertanejo, o calçamento de uma rua e o serviço de lixo são interesses restrictamente locaes, mas, ahi mesmo, a 
detenção dos criminosos e a solução dos conflictos juridicos são interesses geraes. A porcentagem de coexistencia dos interesses locaes e geraes varia com a importancia do logar e a singularidade da sua situação. Numa capital de vulto, como por exemplo São Paulo, os interesses geraes do estado, e os peculiares do municipio, coexistem em proporção que não se sabe ao certo como fixar.

Mas, nem por coexistirem, se ha de concluir que se absorvem. Uns não engolem os outros. Uns não mudam a natureza aos outros. Cada qual conserva as suas caracteristicas inconfundiveis. No municipio da capital de um estado, seja qual for, a limpeza das ruas, por exemplo, ha de ser eternamente interesse peculiar do municipio. Sem duvida, tambem interessa aos bons creditos de todo o estado.

Mas sempre o interesse, o mais directamente local, é tambem interesse "indirecto" de todos. "Peculiar" não é, nem pode ser equivalente á "privativo". Privativo, dizem diccionarios "é o proprio de alguem, ou alguma coisa, de sorte que exclue a outra da mesma generalidade, uso, direito". "E peculiar, diz ainda Moraes, é o proprio, especial e particular". A differença está na idéa de exclusão: "privativo" importa exclusão, e peculiar não. A ordem publica de um estado é seu interesse "peculiar", mas é tambem interesse da nação. Logo, não é "privativo" do estado. Uma escola primaria que certo municipio abra, é seu interesse peculiar, mas não exclusivo, não privativo, porque a instruç̧ão interessa a todo o paiz.

$\mathrm{O}$ entrelaçamento dos interesses dos municipios com os interesses dos estados, e com os interesses da nação, decorre da natureza mesma das coisas. O que os differencia, é a "predominancia", e não a "exclusividade". Ora a coisa interessa directamente ao municipio, como a sua renda e a sua applicação, ora interessa primariamente ao estado, como a sua renda e applicação, ora immediatamente á nação toda, como a sua renda e a sua applicação. Ou, se o exemplo é obscuro, seja: o calçamento de uma 
rua que interessa, primeiramente, ao municipio; a construcção de uma via ferrea, que interessa, antes de á nação, ao estado, e a diplomacia nas relações internacionaes, que interessa, em primeiro logar, á patria. Mas, indirectamente, o calçamento das ruas por todas as cidades do Brasil interessa a todos; a construcção de vias ferreas de norte a sul, de este a leste, interessa á nação toda; a diplomacia que evita as guerras e fomenta o commercio, interessa não menos a cada qual. Não ha, pois, privatividades nos interesses das tres entidades politicas, em que se organisou a federação brasileira: os municipios, os estados e a União.

Os interesses peculiares dos municipios são os que entendem immediatamente com as suas necessidades locaes, e, indirectamente, em maior ou menor repercursão, com as necessidades geraes. Sob certo aspecto, e por alto, todos os interesses são communs; distribuem-se em peculiares a esta ou áquella entidade, quando the aproveita directamente, immediatamente, e só reflexamente ás demais. $O$ estado a todo momento se defronta com todos os municipios. Em todos elles, ha coexistencia de interesses peculiares ao municipio, e interesses directos do estado. A cada um toca prover os que the forem proprios.

Mas não é porque, no territorio de um dado municipio, o volume dos interesses estaduaes seja enorme, que se ha de negar existencia aos interesses peculiares do municipio. Não ha dialectica, em tempo nenhum, em parte nenhuma, com que se possa provar, por exemplo, que a applicação das rendas municipaes, ou o desvelo pelo asseio do mercado, e o embellezamento dos jardins de uma cidade, deixem de ser peculiares a esta cidade ou municipio, só porque esta cidade ou municipio seja a capital de um estado, ou não possua recursos economicos na altura dos serviços que the convem serem feitos.

A realidade insophismavel é existirem, em seja qual for a circumscripção territorial, em que se divide o estado, 
interesses peculiares ao logar, ao lado de interesses geraes. $E$, na esphera dos interesses peculiares aos municipios, nem o estado, nem a União podem decidir. E, quando ahi ponham as suas mãos, ferem a autonomia dos municipios, como thes foi promettido pelo art. 68 da constituição federal.

\section{LEIS ORGANICAS}

Mas a quem ha de caber a determinação das linhas divisorias entre os interesses peculiares dos municipios e os demais? A quem incumbe fixar as balisas, para circumscrever a orbita, dentro da qual os municipios têm o governo de si mesmos?

Se fossem os proprios municipios, passariam elles a ser soberanos. Mas, como são apenas autonomos, não lhes pode ser da alçada traçar fronteiras á sua propria competencia.

Em não sendo os municipios, só podem ser o estado e a União. São os dois unicos poderes acima do seu.

A politica, entre nós, tem attribuido aos estados a faculdade de decretar leis organicas dos municipios. Se os usos fazem lei "super-suprema", ou lei contra a Magna Carta, é aos estados que incumbe a missão constitucional de organizar a autonomia dos municipios. E' a lição da politica nacional. Com liberalidade ou com estreiteza, os estados brasileiros elaboraram leis organicas para os seus municipios.

Não obstante, lhes fallece competencia para tanto. O que se tem feito, é cahir de abuso em abuso, caminho da centralização imperial, que a Republica aboliu. E a constituição federal é a suprema lei do paiz; ainda que antigas, não podem as praticas abusivas prevalecer contra ella.

Ora bem. $\mathrm{O}$ artigo 34 da constituição federal dispõe sobre a competencia "privativa" do Congresso nacional. O que ahi se enumera, só ao Congresso cabe. Muito de intento, cautelosamente, a constituinte dividiu a 
competencia do Congresso em privativa, e não privativa. No artigo 34, preceituou: "compete "privativamente" ao Congresso Nacional"; e, no artigo 35, declarou . "incumbe, outrosim, ao Congresso, mas "não privativamente":

Competencia privativa quer dizer competencia propria com exclusão dos demais, ou de intervenções alheias. A concomitancia é precisamente o opposto da privatividade. Tudo, pois, que for attribuição privativa do Congresso nacional, não é da competencia dos outros orgãos da soberania, e, muito menos, dos poderes estaduaes. Logo, tudo o que os estados fizeram contra uma attribuição "privativa" do Congresso nacional, é irremediavelmente nullo e de nenhum effeito. Não importa que seja constante e habitual a pratica illegal. A inconstitucionalidade não muda de natureza com a edade, e a calvice que a marque.

Quando a Constituição declara que é da competencia privativa do Congresso nacional "criar bancos de emissão", ou "legislar sobre o direito civil, commercial e criminal da Republica", claro está que prohibiu ás assembléas estaduaes legislarem sobre direito substantivo, ou fundarem bancos de emissão. Quando, porém, diz que incumbe ao Congresso Nacional, mas não privativamente, "criar institutos de ensino superior e secundario nos estados", não menos evidente é que permittiu ás legislaturas estaduaes organisarem e manterem gymnasios e faculdades superiores.

Em summa, sempre que a competencia for privativa do Congresso nacional, não podem os governos estaduaes exercel-a, senão em flagrante rebeldia á lei das leis. Ser legalista é essencialmiente ser obediente á Magna Carta. Quem faz prevalecer uma situação permanente contra ella está, dos pés á cabeça, fóra da lei.

Ora, o artigo 34, item 34 , da constituição, estatue:

"Compete privativamente ao Congresso nacional, decretar as leis organicas para a execução completa da constituição". 
Nenhum estado, pois, póde decretar leis organicas para a execução completa da constituição, isto é, para a execução dos principios que ella consigna, e dos institutos politicos e administrativos, que ella criou.

A autonomia dos municipios é, evidentemente, parte integrante da constituição, é, na federação que adoptou, um dos seus principios maximos, uma das suas magnas instituições politicas e administrativas.

E como se ha de executar a constituição no tocante á autonomia dos municipios?

Mediante uma lei organica.

Mas as leis organicas, para á execução completa da constituição, só podem ser decretadas pelo Congresso nacional.

Logo, são inconstitucionaes as leis organicas, que os estados têm decretado, sobre a constituição dos seus municipios.

Salvo, se a execução do principio da autonomia municipal se exclue da execução completa da constituição.

Mas como ninguem ousará firmar este disparate, força é concluir que a lei organica dos municipios deve ser federal, e não estadual.

O não haver, até hoje, o Congresso nacional decretado lei organica sobre a execução constitucional da autonomia dos municipios não é argumento que colha. As assembléas politicas não morrem de amores pelas constituições, sobretudo quando geradas de um golpe, em logar de crystallisadas pelos usos e costumes. Não é só neste passo que a constituição brasileira tem sido golpeada e mutilada.

Mas, dentro do respeito que lhe é devido, uma lei organica federal deve fixar os limites, entre cujos horizontes se ha de exercer a autonomia dos municipios. Emquanto o não fizer, a autonomia não passará, como não passa, de dadiva ou graça dos partidos olygarchicos, que lhes têm decretado leis organicas. 


\section{O SEGUNDO ELEMENTO}

Mas traçados por outro poder os limites que não podem transpôr, os municipios têm a faculdade autodeterminante na esphera dos seus interesses peculiares.

Esta faculdade autodeterminante é o segundo elemento da autonomia municipal. $\mathrm{O}$ primeiro são as raias de competencia, que uma lei federal deve fixar E o segundo, a autodeterminação dentro destas extremas.

Ora, este segundo elemento, apesar da sua significação intuitiva e meridiana, tem sido igualmente menosprezado, sophismado e, ás vezes, mutilado e destruido, principalmente pela obscuridade com que o encaram, e pelo imperialismo com que o tratam.

Autonomia sem autodeterminação é ser e não ser ao mesmo tempo, e nas mesmas relações. E autodeterminação é determinação propria e exclusiva. Não apenas propria ou peculiar, mas exclusiva ou privativa.

Privativa de que?

De outro qualquer poder.

E quaes são estes outros poderes, cuja interferencia seria possivel na orbita das franquias municipaes?

Só ha dois. o estado e a União.

Logo, a autonomia dos municipios importa, necessariamente, na exclusão dos poderes do estado ou da União, em tudo quanto thes respeitar ao peculiar interesse.

Excluidos os poderes estranhos, só resta o proprio, e, só por isto, é que é autonomo o municipio.

Com as mãos livres para cuidar de seus peculiares interesses, deve começar o municipio por organisar o seu proprio governo. Em que pese á opinião geral contra o direito de se organisarem, não é lá de grande equilibrio rejeitar os corollarios das premissas que se adoptem. Se se reconhece a autonomia aos municipios, força é, logicamente, admittir tudo o que da autonomia se desdobre E uma das consequencias que della decorre, é o direito de se 
organisarem dentro das balisas que uma lei federal thes deve oppor. Desde que um poder estranho the orgarise o governo, já o municipio não é senhor de si, não é autonomo. Se se entende que o direito de se organisarem é demais ou perigoso, então reforme-se a constituisão federal, para the riscar a liberalidade da autonomia municipal. Deixar ao municipio, como autonomia, apenas o poder de haver-se dentro dos moldes que lhe forem impostos, é conceder-lhe a liberdade dos que pódem agir, contanto que procedam deste e não daquelle modo. $\mathrm{Na}$ sua casa, um pae só é autonomo em educar os seus filhos, se puder escolher livremente o systema a que vae submettel-os, e, dentro deste systema, proceder como melhor lhe pareça. Mas se apenas puder agir livremente dentro do systema que the impuzeram, então já não é autonomo.

A restriç̧ão constitucional á autonomia dos municipios é a peculiaridade dos seus interesses. Dentro delles, a constituição the firmou o poder de autodeterminação, ou governo proprio. Logo, pódem elles organisar e escolher o systema do governo que tenham por melhor, e, dentro da organisação que elegerem, proceder pela forma que mais de accôrdo sintam com os seus interesses proprios.

Certo, o direito de se organisarem não transcende os horizontes da autonomia, para equivaler á soberania. Mas, ainda aqui, é a propria constituição federal quem decide, com lhe oppor novas divisas.

$\mathrm{Na}$ conformidade do seu artigo 63, "Cada estado reger-se-á pela constituição e pelas leis que adoptar, "respeitando os principios constitucionaes da União" Ora, se os estados, cuja autonomia se exerce em campo muito mais vasto, são obrigados á obediencia aos principios constitucionaes da União, com maiores razões os municipios. Além, pois, do limite dos seus interesses peculiares, aos municipios se erguem, como muralhas intangiveis e sagradas, os principios constitucionaes da União.

No exercicio do direito de se organisarem, os municipios não pódem perfilhar, por exemplo, o governo di- 
recto, porque a isto se oppõe um dos principios constitucionaes da União; não pódem instituir o governo hereditario, perpetuo e irresponsavel, porque a isto se oppõem certos principios constitucionaes da União. Os municipios têm de respeitar o systema representativo e a electividade, a temporariedade e a responsabilidade do governo que organizarem.

Este governo se ha de estructurar de dois orgãos: o legislativo e o executivo municipal. Não tem o terceiro orgam, porque a peculiaridade dos seus interesses não admitte funcções judiciaes. Estas são de interesse geral do estado ou da União.

Mas ainda: No cumprirem a electividade do executivo municipal, não pódem ferir o presidencialismo que é outro dos principios constitucionaes da União. No systema opposto, o parlamentar, quando o governo é republica, o chefe do executivo é eleito pelo parlamento. Mas no regimen presidencial, o chefe do executivo tem de ser eleito directamente pelo povo, em um só escrutinio, ou dois, mas sempre eleito pelo povo. Logo, o prefeito municipal, como chefe que é do executivo, não póde ser criatura do legislativo municipal, como é de uso na grande maioria dos municipios, em estados onde alguma coisa da constituição se acata.

As leis organicas dos municipios, decretadas pelos estados, já são de origem inconstitucionaes. Dobram a sua inconstitucionalidade, negando aos municipios o direito de se organizarem. Redobram-na, em seguida, ordenando a eleição de chefe do executivo municipal pelos vereadores ou intendentes.

Que se dirá, então, da nomeação de prefeitos pelos governadores dos estados?

E' a ultima palavra da inconstitucionalidade, o golpe de morte, a degolla, em plena rua, da autonomia dos municipios. Porque, assentada a autonomia municipal, quem determina os impostos a serem pagos? 
Os proprios municipes, os contribuintes, não directamente, mas por meio dos seus representantes.

Mas é autonomia apenas determinar que impostos devem pagar, como, na fabula, para aquella pobre victima, cuja gabada liberdade estava em escolher o molho com que devia ser comida?

Evidentemente não. A autonomia municipal reside principalmente na autodeterminação do emprego do dinheiro dos municipes para a satisfacção dos interesses peculiares ao municipio. Quem ha de executar as leis municipaes, hão de ser os proprios municipes por meio do seu representante, o prefeito, desde que se tenha por adoptada a autonomia. Dos seus peculiares interesses é este talvez o maior de todos.

Considere-se a principal differença entre o regimen unitario do Imperio, e o regimen federativo da Republica no Brasil. Naquelle, as provincias não eram autonomas. Nesta, tão grande foi a sua autonomia, que até mudaram de nome para estados. Mas, no systema unitario, o povo das provincias alegia as suas assembléas. Não elegia, porém, o chefe do poder executivo. Este era nomeado pelo imperador. Não era a vontade popular que o designava. Mas a vontade do centro, a vontade pessoal do chefe da nação. Já no systema de autonomia das provincias, isto é, no systema federativo, não só o congresso é de eleição popular, mas principalmente o chefe do poder executivo. O centro, o governo da União, não pode indicar, nomear, ou influir na escolha dos governadores dos estados. No dia em que o pudesse fazer, lá se ia por agua abaixo a autonomia estadual. O que caracteriza, e quasi por si só constitue a autonomia estadual, é o direito que tem o povo de cada estado, de escolher livremente o chefe do seu poder executivo.

Da mesma forma em relação aos municipios. Se se lhe quer estabelecer a autonomia, não basta que os munisipes elejam a camara legislativa. Isto seria compativel com o regimen unitario, como no Imperio. Mas é essen- 
cial que elejam, a seu alvedrio, o chefe do executivo municipal. Nesta eleição, é que está quasi toda a alma da autodeterminação local. A electividade dos prefeitos é o coração da autonomia municipal, é a espinha dorsal do artigo 68 da constituição da Republica.

Como se ha de admittir, então, que sejam elles escolhidos á revelia do povo, continuando o povo autonomo? Esmaga-se a espinha dorsal, estraçalha-se o coração, evapora-se a alma de uma entidade, e, depois, ainda se ha de suppôr que esta entidade exista e tenha vida, e pompeie de exuberancias!

Em resumo:

A autonomia dos municipios, que a constituição federal, no seu artigo 68, assegura, vem a ser o poder da autodeterminação dos municipes em tudo quanto entenda com o seu peculiar interesse.

Uma lei federal deve, nos termos do art. 34 da constituição, definir, delimitar a peculiaridade dos interesses municipaes. Esta peculiaridade jamais se confunde com privatividade. São idéas que se aproximam, mas não se misturam.

Além do limite dos seus interesses proprios, ainda os municipios, ao se organisarem, se acham obrigados a respeitar os principios constitucionaes da União.

Dentro destas duas ordens de barreiras, é que podem agir livremente. Dahi a sua autonomia, que se compõe:

a) do direito de se organisarem, e

b) do de elegerem o seu poder legislativo e o seu poder executivo.

$\mathrm{E}$, destas duas eleições, a que mais lhe importa, é a eleição directa do prefeito. 